\title{
What do NHS staff think about the NHS?
}

\author{
The government put out some upbeat survey results about NHS staff attitudes towards the health \\ service. But, questions John Appleby, do the figures suggest a growing pessimism about the \\ future?
}

\author{
John Appleby chief economist
}

King's Fund, London, UK

The publication last month of the NHS satisfaction results from the 2011 British Social Attitudes survey (with questions on healthcare sponsored by the King's Fund) caused a good deal of comment. ${ }^{1}$ The survey of 1096 people showed that satisfaction with the NHS overall had fallen by 12 percentage points-from $70 \%$ (based on a sample of 3297) to 58\% — between 2010 and 2011. This is a statistically significant drop, and the biggest in one year since the survey began in 1983. It was therefore perhaps unsurprising that the survey attracted a lot of attention - and some criticism - not least from the Department of Health.

A key criticism was that the survey did not reflect any real change in the actual performance of the NHS because it was a survey of the public and not patients. The implication was that the public - not having had intimate contact with the NHS - would know nothing of the NHS and so the opinions were in effect worthless (at least in telling us anything about the NHS).

Of course, many people who participated in the British Social Attitudes survey will have had recent contact with the NHS. Leaving aside the fact that the point of the survey is precisely to find out about people's attitudes (as it says on the tin), part of the Department of Health's response to the survey was to bring forward publication of two of its own commissioned surveys: one on public perceptions of the $\mathrm{NHS}^{2}$ and the other on NHS staff attitudes. ${ }^{3}$

Both these surveys to some extent contradicted the British Social Attitudes survey results. The department's public poll of 1001 people showed satisfaction with the running of the NHS at $70 \%$ in December 2011 - exactly the same proportion as in the previous year. And the survey of 1130 NHS staff showed that in winter 2011 the proportion of staff satisfied with the way the NHS delivers care in their local area to be $76 \%$ (fig $1 \Downarrow$ ). This was down a statistically insignificant three percentage points on the previous year, but was still significantly higher than the British Social Attitudes survey's measly looking 58\% satisfaction with the NHS.
The differences between the three polls will be down to a combination of factors, including sample size, question wording, the sample (public, NHS staff), the sampling frame methods (how people were recruited), the context of the polls (the British Social Attitudes health questions are part of a much larger non-health questions survey), and timing of the fieldwork. Without a specially constructed controlled trial we cannot quantify the relative contributions of these factors to differences in the results.

But did the British Social Attitudes survey produce a particularly pessimistic view of the NHS? Perhaps not. From the NHS staff attitudes survey, it is interesting that NHS managers-which, as the survey noted, traditionally tend to be the group most positive about the NHS - saw their satisfaction fall 10 percentage points from $87 \%(n=212)$ in the spring of 2010 to $77 \%(n=201)$ in the winter of 2011 . This change was significant at $\mathrm{P}=0.05$, as are all the differences between years quoted from this survey.

Other questions from the NHS staff survey suggest that they may also hold rather pessimistic views. For example, asked whether they thought that their local NHS services had got better, worse, or stayed the same in the last 12 months, 29\% said services had got worse - the same as in the winter of 2010 , but as figure $2 \Downarrow$ shows, a 10 point increase on the autumn 2009 result.

Among general practitioners there was a 30 point increase (from $17 \%(n=200)$ to $47 \%(n=200))$ between the summer of 2009 and winter 2011 in those stating things had got worse; and there was a 15 point increase (to $31 \%, \mathrm{n}=200$ ) among hospital doctors and a 13 point increase (to $21 \%, \mathrm{n}=200$ ) among managers.

Another question in the NHS staff survey asked whether services would improve over the next few years. The winter 2011 results show that, for the first time, a majority of staff $(53 \%, n=1130)$ felt things would get worse; the net "better" (that is, better minus worse) reached its largest negative gap of 29 percentage points (fig $3 \Downarrow$ ). 
Again, the results for this question for individual staff groups suggest a growing pessimism about the future. In 2011, 61\% $(n=200)$ of GPs thought services would get worse over the next few years - up 17 points on the summer of 2009 - and over half $(53 \%, n=202)$ of managers surveyed agreed - up by 22 points on their views in 2009 (fig $4 \Downarrow$ ).

Competing interests: The author has completed the ICMJE unified disclosure form at www.icmje.org/coi_disclosure.pdf (available on request from the corresponding author) and declares no support from any organisation for the submitted work; no financial relationships with any organisation that might have an interest in the submitted work in the previous three years; and no other relationships or activities that could appear to have influenced the submitted work.
Provenance and peer review: Commissioned; not externally peer reviewed.

1 Appleby J. Public satisfaction with the NHS and its services. King's Fund, 2012.www. kingsfund.org.uk/current_projects/bsa_survey_results_2011/index.html.

2 Ipsos Mori Social Research Institute. Public perceptions of the NHS and social care: an ongoing tracking study conducted for the Department of Health, December 2011. www. dh.gov.uk/health/files/2012/06/Public-Perceptions-of-the-NHS-Tracking-Survey-December2011-Report-v1-FINAL-080612-PUBLIC.pdf

3 GfK NOP Social Research. NHS staff tracking research-winter 2011 (research wave 6). A research report for the Central Office of Information on behalf of the Department of Health. 2012. www.dh.gov.uk/health/files/2012/06/NHS-Staff-Tracker-Wave-6-ReportFinal-June-2012.pdf.

Cite this as: BMJ 2012;345:e5130

๑๑ BMJ Publishing Group Ltd 2012 


\section{Figures}

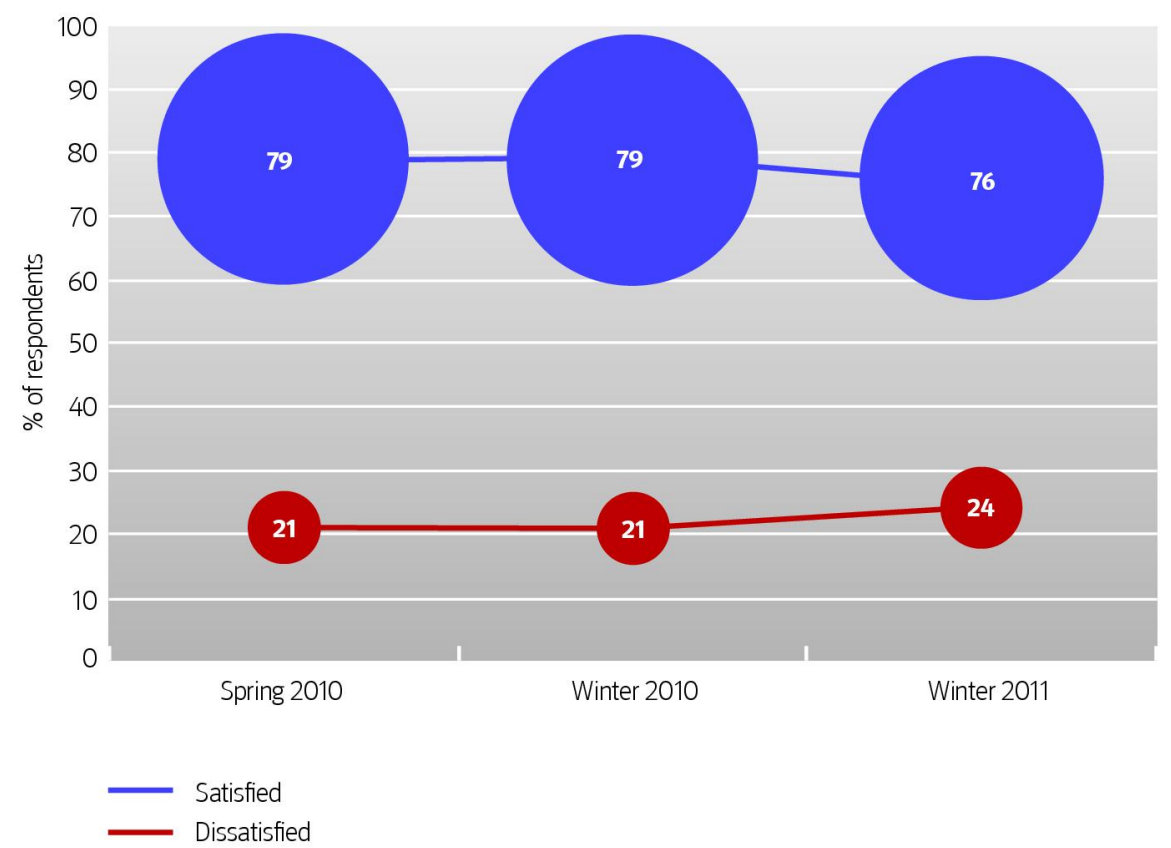

Fig 1 Response to NHS staff survey question: "How satisfied or dissatisfied would you say you are with the service the NHS currently delivers to patients in your local area?" (All NHS staff groups: sample sizes for spring 2010, winter 2010, and winter 2011 were 1124, 1001, and 1130 respectively $)^{3}$ 


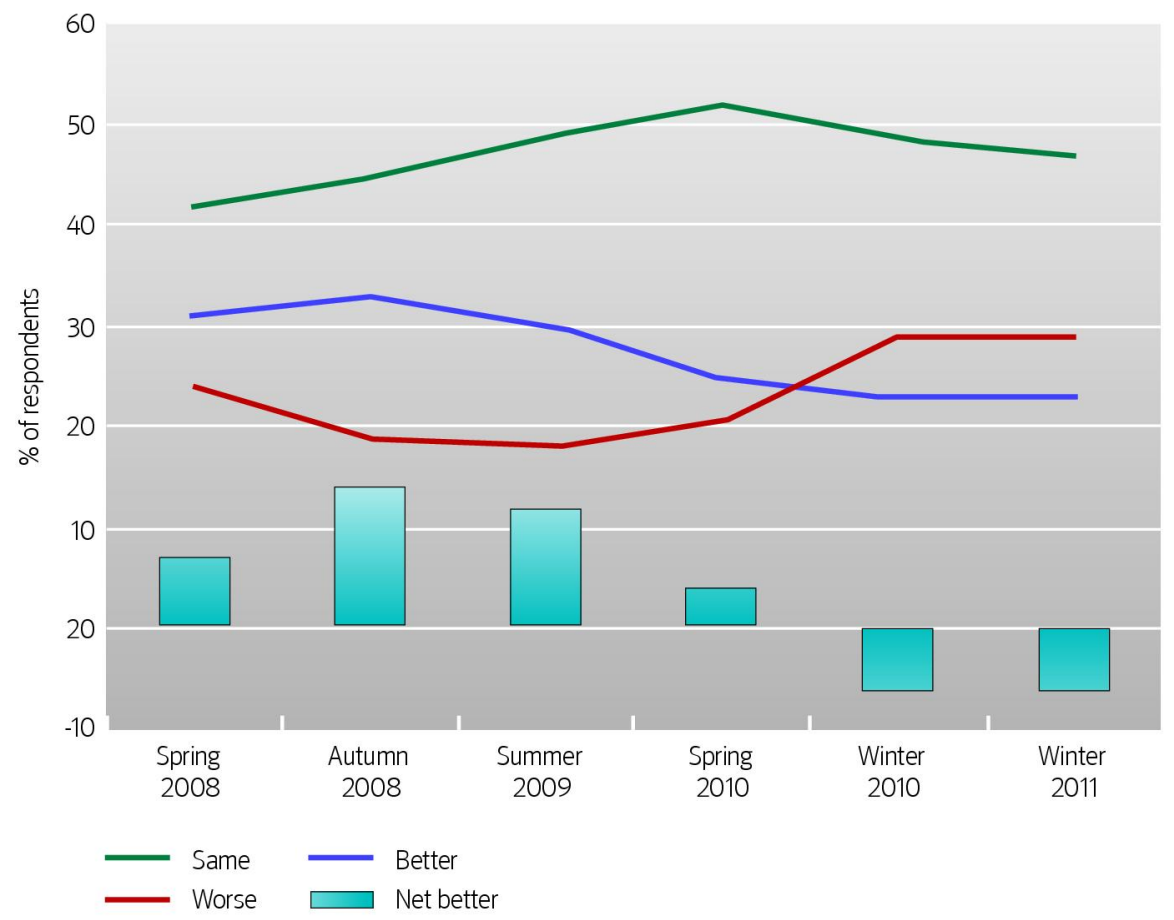

Fig 2 Response to NHS staff survey question: "And still thinking about the NHS in your local area, in the past 12 months, do you think it has got better, got worse or stayed the same in terms of patient care?"3 Sample sizes for each survey from spring 2008 onwards were 908, 934, 1113, 1124, 1001, and 1130 respectively 


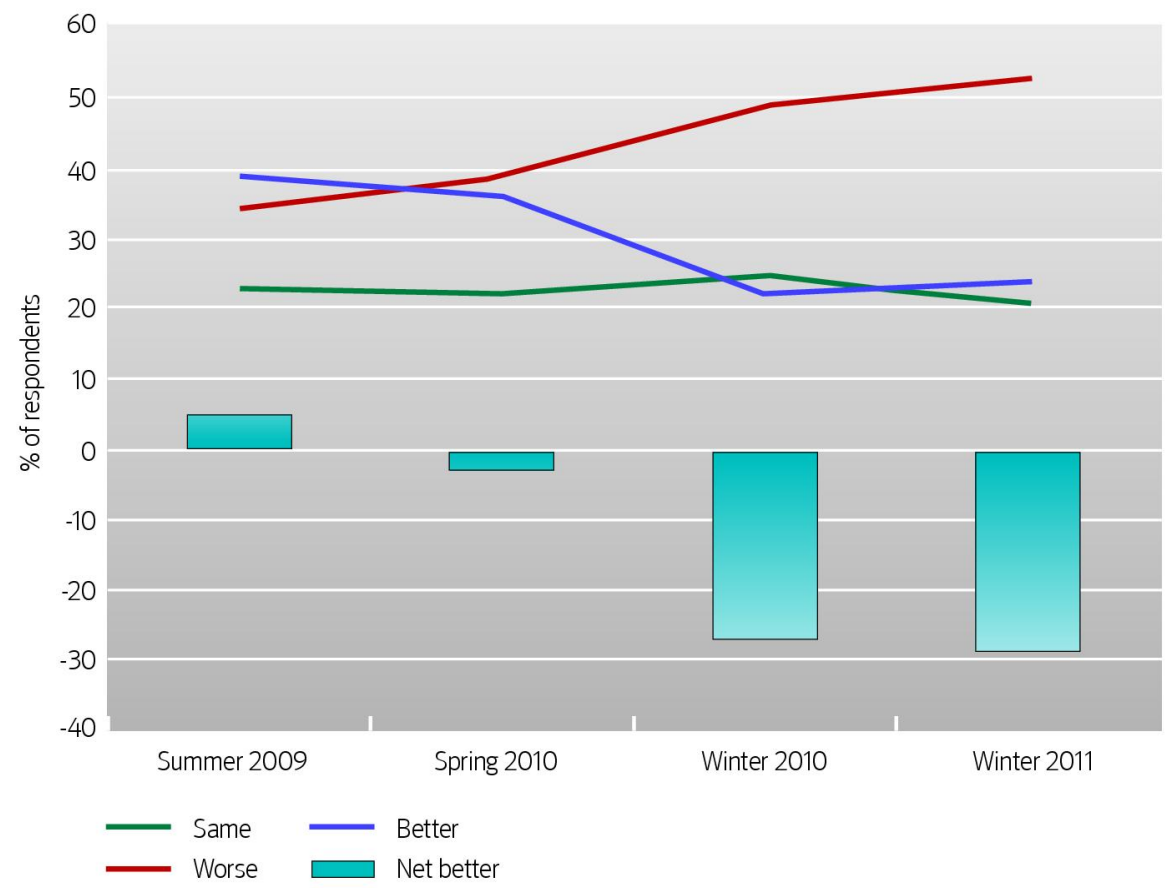

Fig 3 Response to NHS staff survey question: "Thinking about the care the NHS delivers to patients: over the next few years do you expect it to get better, worse or stay about the same?"3 Sample sizes for each survey from spring 2008 onwards were $908,934,1113,1124,1001$, and 1130 respectively 


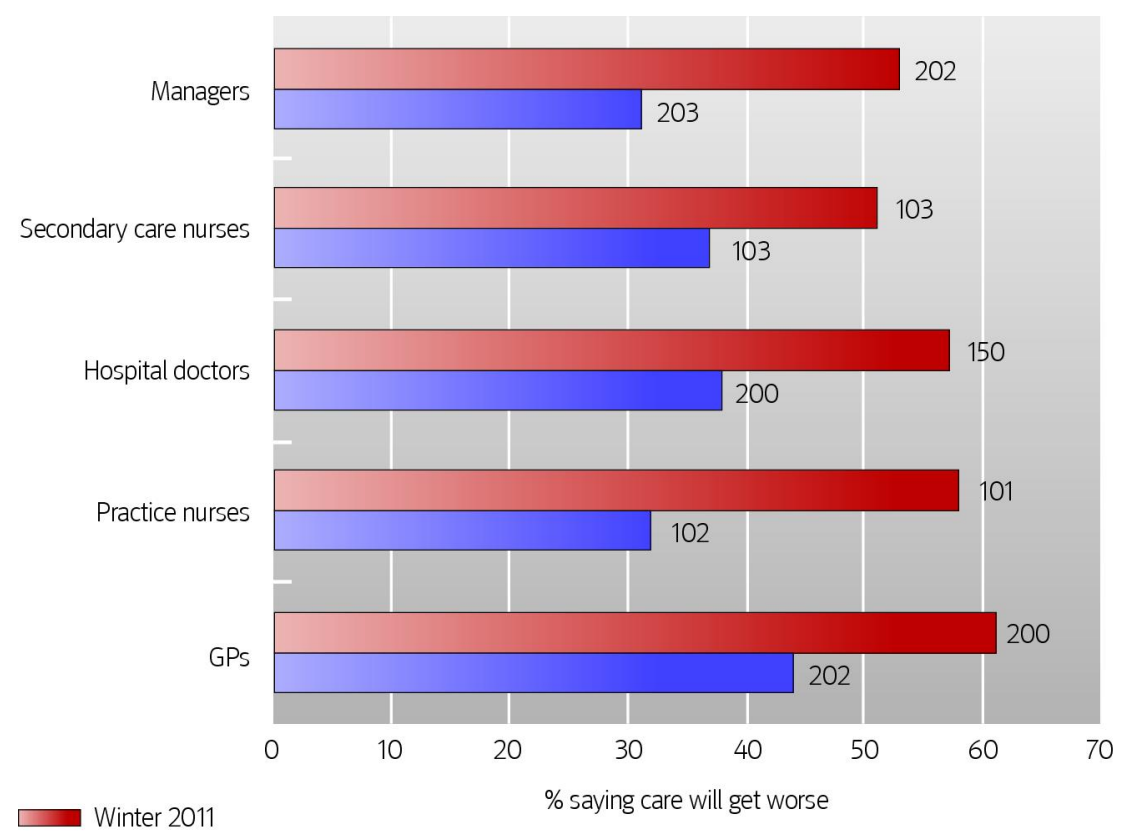

$\square$ Summer 2009

Fig 4 Response to NHS staff survey question: "Thinking about the care the NHS delivers to patients: over the next few years do you expect it to get better, worse, or stay about the same?"3 Total sample size for each group at end of each bar 